\title{
Comparison of intrathecal and intravenous clonidine on attenuating haemodynamic response to capnoperitoneum
}

\author{
R Sripriya ${ }^{1}$, Ashok Arjun $^{2}$, P Rani $^{{ }^{*}}$, M Ravishankar $^{3}$ \\ Associate Professor ${ }^{\prime *}$, Senior resident ${ }^{2}$, Professor and Dean ${ }^{3}$, Mahatma Gandhi Medical College and \\ Research Institute, Sri Balaji Vidyapeeth University, Pondicherry, India.
}

\begin{abstract}
Background and aims: Clonidine has been used via different routes to suppress the haemodynamic stress responses associated with capnoperitoneum. This study was designed to compare the stress response attenuating effect of equal doses of intrathecal (IT) and intravenous (IV) clonidine during capnoperitoneum under general anaesthesia.
\end{abstract}

\begin{abstract}
Method: Seventy-five patients satisfying inclusion criteria were randomly allocated to three groups of 25 patients each. Group C-IV patients received $1 \mu \mathrm{g} / \mathrm{kg}$ i.v. clonidine, $15 \mathrm{mins}$ before induction. Group C-IT patients received the same dose intrathecally just before induction. Group $\mathrm{N}$ was the control group. Intraoperative haemodynamic parameters, post-operative pain and sedation were assessed. Patients requiring nitroglycerine (NTG) to maintain mean arterial pressure (MAP) below $20 \%$ of baseline were noted.
\end{abstract}

Results: There was a statistically significant difference $(\mathrm{p}=0.04)$ in the number of patients who required NTG between group C-IT and group C-IV [0\% vs $16 \%(\mathrm{p}=0.04)]$ and between group C-IT and group $\mathrm{N}[0 \%$ vs $36 \%(\mathrm{p}=0.001)]$. Rescue analgesia was required in 16 patients in group $\mathrm{C}$-IV, 10 patients in group $\mathrm{C}$-IT and 20 patients in group $\mathrm{N}$ in the first two hours after surgery. None of the patients in either group were deeply sedated at tracheal extubation.

Conclusion: At $1 \mu \mathrm{g} / \mathrm{kg}$, IT clonidine is more effective than IV clonidine in suppressing haemodynamic stress response to capnoperitoneum. Both IT and IV clonidine provide early post-operative analgesia without causing much sedation.

Keywords: Laparoscopy; physiological stress; clonidine; spinal anaesthesia

\section{Introduction}

Capnoperitoneum during laparoscopy causes significant haemodynamic changes. ${ }^{1-4}$ Pharmacological agents like $\beta$-blockers, opioids, nitroglycerine and dexmedetomidine have been used to minimize such derangements with varied results. ${ }^{5-9}$ Nitroglycerine (NTG) is commonly used as a rescue measure for intraoperative hypertension. ${ }^{10,11}$ Clonidine, an $\alpha-2$ adrenoreceptor agonist, reduces sympathetic outflow and is advantageous in laparoscopic procedures. $^{12}$ In addition, $\alpha-2$ agonists also induce analgesia by acting at different sites; the brain, brain stem, spinal cord and peripheral nerves. ${ }^{13}$

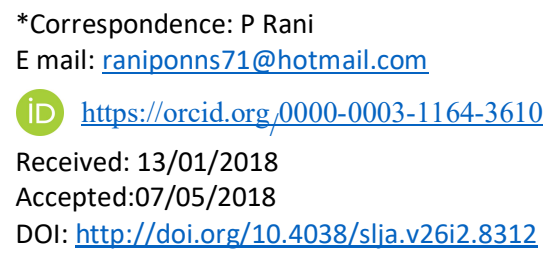

Clonidine can be administered via various routes [oral, intramuscular (IM), intravenous (IV), intrathecal (IT), epidural] and used in doses ranging from $1-8 \mu \mathrm{g} / \mathrm{kg} .{ }^{14-17}$ At equal doses, IT clonidine has been shown to produce better analgesia than IV clonidine. ${ }^{18}$ The effect of IT clonidine on maintaining haemodynamic stability during laparoscopic procedures has not been studied so far. This study was designed to compare the stress response attenuating effect of equal doses of IT and IV clonidine during capnoperitoneum. Our primary objective was to assess the number of patients requiring NTG to maintain mean arterial pressure (MAP) within $20 \%$ of baseline. Secondary objectives were to assess the post-operative pain and sedation.

\section{Methodology}

After approval from the Institutional Ethics Committee (PG/2014/122), this randomized prospective observer blinded study was conducted at a tertiary care hospital from 
January 2015 to July 2016. American Society of Anaesthesiologists (ASA) physical status 1 and 2 patients, between the age group $18-65$ years admitted for laparoscopic surgeries (cholecystectomy, appendectomy, diagnostic laparoscopy) under general anaesthesia (GA) formed the study population.

After pre-anaesthetic assessment, 75 patients were selected from study population using a random table. Written informed consent for participation was obtained. Exclusion criteria were patient refusal for spinal, expected pneumoperitoneum duration less than 60mins, laparoscopic surgeries requiring steep head low or head up positions, A-V conduction block, HR $<55$ beats/min, hypertensive patients and any other absolute contraindications for spinal anaesthesia.

All patients who participated in the study were kept nil per oral for a period of at least $6 \mathrm{hrs}$ for solids and $2 \mathrm{hrs}$ for clear fluids. They were premedicated with alprazolam $0.5 \mathrm{mg}$ and ranitidine $150 \mathrm{mg}$ per oral on the night before surgery and morning of surgery. On the day of surgery, an 18G IV cannula was secured and preloading with $500 \mathrm{ml}$ of Ringer Lactate solution was done in the pre-operative holding area. Midazolam $0.02 \mathrm{mg} / \mathrm{kg}$ was administered IV. Patients were randomized by an independent person to either IV clonidine (C-IV), IT clonidine (C-IT) or control $(\mathrm{N})$ group by sealed envelope technique. Baseline blood pressure and HR were recorded in the pre-operative holding area, before administration of the study drug.

In the C-IV group, $1 \mu \mathrm{g} / \mathrm{kg}$ clonidine hydrochloride (Cloneon, Neon laboratories) was administered diluted in $100 \mathrm{ml}$ normal saline over $15 \mathrm{mins}$ in the pre-operative holding area under standard monitoring. (Figure 1) After infusion, patients were shifted to operation theatre (OT) and GA was induced. In the C-IT group, $1 \mu \mathrm{g} / \mathrm{kg}$ (maximum of $75 \mu \mathrm{g}$ ) preservative free clonidine was given in L3-L4 interspace diluted with $1.5 \mathrm{ml}$ cerebrospinal fluid (CSF), following which GA was administered.

In OT, monitoring (GE S5 Anaesthesia monitor, GE Healthcare, United States) included electrocardiography, pulse oximetry, noninvasive blood pressure, minimal alveolar concentration (MAC) of anaesthetic agent, $\mathrm{EtCO}_{2}$ and train of four (TOF) (Organon Ltd. Ireland) for neuromuscular blockade.

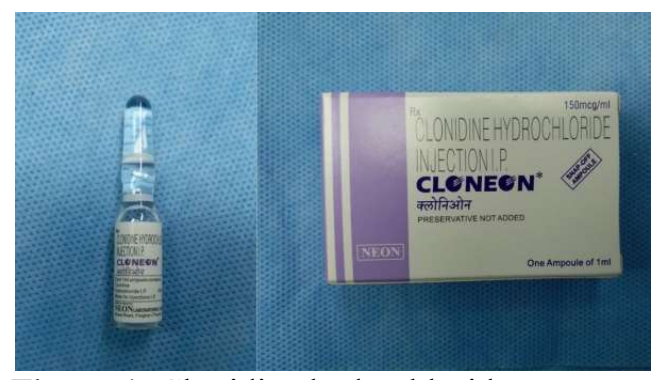

Figure 1: Clonidine hydrochloride

After pre-oxygenating with $6 \mathrm{~L} / \mathrm{min}$ of $\mathrm{O}_{2}$ for 3 mins, patients were induced with fentanyl $2 \mu \mathrm{g} / \mathrm{kg}$ and propofol $2 \mathrm{mg} / \mathrm{kg}$. Vecuronium bromide $0.1 \mathrm{mg} / \mathrm{kg}$ was administered, and patients were mask ventilated with $6 \mathrm{~L} / \mathrm{min}$ flow using a mixture of $33 \%$ oxygen, $66 \%$ nitrous oxide $\left(\mathrm{N}_{2} \mathrm{O}\right)$ and $1.5 \%$ dial concentration of isoflurane for 3 minutes. Tracheal intubation was done when TOF count was 0. After conformation of proper endotracheal tube placement, intermittent positive pressure ventilation was instituted, with tidal volume of $8 \mathrm{ml} / \mathrm{kg}$ lean body mass and respiratory rate $12 /$ min and adjusted to maintain $\mathrm{EtCO}_{2}$ between $30-35 \mathrm{mmHg}$. After 10 minutes on high flow, anaesthesia was maintained with $800 \mathrm{ml}$ fresh gas flow with $\mathrm{O}_{2}, \mathrm{~N}_{2} \mathrm{O}$ ratio of 50:50 and 1.5\% dial concentration isoflurane. Isoflurane was adjusted accordingly to maintain a minimum alveolar concentration (MAC) - of 1.0. During laparoscopy, intra-abdominal pressure (IAP) was maintained at $12 \mathrm{mmHg}$. Haemodynamic parameters were recorded by a blinded observer before induction, before intubation, every $5 \mathrm{mins}$ after intubation, before carbon-di-oxide $\left(\mathrm{CO}_{2}\right)$ insufflation and then every $5 \mathrm{mins}$ for $60 \mathrm{mins}$ of capnoperitoneum. Time of initiating and ending capnoperitoneum and end of surgery were also noted. Intermittent boluses of $0.02 \mathrm{mg} / \mathrm{kg}$ vecuronium were administered when TOF count was 2. Fentanyl i.v. was repeated at doses of $0.5 \mu \mathrm{g} / \mathrm{kg}$ every hour.

An increase in MAP beyond $20 \%$ of baseline value was managed with NTG infusion starting at $0.3 \mu \mathrm{g} / \mathrm{kg} / \mathrm{min}$ and titrated with $0.1 \mu \mathrm{g} / \mathrm{kg} / \mathrm{min}$ increments every 5 mins till it was within limits. Once initiated, NTG was tapered and stopped only when MAP fell below the baseline MAP level. Any fall in systolic blood pressure(SBP) below $80 \mathrm{mmHg}$ or MAP below $60 \mathrm{mmHg}$, was treated with $3 \mathrm{mg}$ boluses of mephenteramine. A decrease in HR to less than $50 / \mathrm{min}$ was treated with $0.3 \mathrm{mg}$ of i.v. atropine. 
Isoflurane was stopped after deflating the abdomen and the ports were taken out. After application of dressing, reversal of neuromuscular blockade was done when TOF count was 2, following which $\mathrm{N}_{2} \mathrm{O}$ was stopped and fresh gas flows increased to $8 \mathrm{~L} / \mathrm{min}$. Tracheal extubation was done when respiratory parameters were adequate, and patient was responding to oral commands. After tracheal extubation, pain and sedation were recorded at thirty-minute intervals for two hours. Pain was graded on a numeric pain rating scale of 0 to 10 and graded as no pain (0), mild pain (1-3), moderate pain (4-6) or severe pain (7-10). Paracetamol 1gm was administered i.v. when patient complained of moderate pain. Sedation was recorded on a five-point scale (0- Awake, agitated; 1- Awake, comfortable; 2- Asleep, arousable; 3- Asleep, sluggish response to command; 4- No response to verbal command or touch). ${ }^{10}$

The incidence of hypertension in laparoscopic surgeries has been reported to be $46.7 \%$ by. ${ }^{10}$ Based on this study, sample size was calculated to detect a $40 \%$ reduction in the incidence of hypertensive response in C-IT group when compared to control group, with an alpha error of 0.05 and power of $80 \%$ using the formula $\mathrm{n}=$ $(\mathrm{a}+\mathrm{b})^{2}\left[\mathrm{p}_{1} \mathrm{q}_{1}+\mathrm{p}_{2} \mathrm{q}_{2}\right] / \mathrm{x}^{2}[\mathrm{a}=1.96, \mathrm{~b}=0.842, \mathrm{p} 1=$ 46.7, $\mathrm{q} 1=53.3, \mathrm{p} 2=18.68, \mathrm{q} 2=81.3]$. The sample size was calculated to be 19 patients in each group. Taking into account the drop outs, 25 patients were included in the study.

Sample size calculation: All data were entered into a Data Collection Proforma Sheet and were entered into Excel (MS Excel 2010). Statistical analysis was carried out using SPSS version 16.0 (IBM SPSS, US) software. Descriptive data were reported as mean \pm standard deviation. Sex and ASA status was analyzed using Kruskal Wallis test. Age, duration of pneumoperitoneum and duration of surgery were analyzed using one-way ANOVA. Haemodynamic data were analyzed using repeated measures ANOVA with post-hoc test for comparison between the groups. Chi-square test was used for number of patients requiring NTG. Post-op pain and sedation was analyzed using Chi square test and Mann Whitney test.

\section{Results}

Seventy-five patients were enrolled in the study. They were randomized into three groups. The groups were comparable in terms of age, sex distribution, ASA physical status, duration of pneumoperitoneum, duration of surgery and type of surgery (Table 1).

Table 1: Demographic data.

\begin{tabular}{|c|c|c|c|c|}
\hline Parameter & $\begin{array}{l}\text { Grou } \\
\text { p C- } \\
\text { IV } \\
(n=25 \\
\end{array}$ & $\begin{array}{l}\text { Group } \\
\text { C-IT } \\
(n=25)\end{array}$ & $\begin{array}{l}\text { Group } \\
N \\
(n=25)\end{array}$ & $\begin{array}{l}\mathbf{P} \\
\text { Value }\end{array}$ \\
\hline Age (Years) & $\begin{array}{l}36 \pm 1 \\
2 \\
\end{array}$ & $32 \pm 10$ & $36 \pm 10$ & $\begin{array}{l}0.38 \\
5 \\
\end{array}$ \\
\hline Sex (M: F) & $8: 17$ & $11: 14$ & $11: 14$ & $\begin{array}{l}0.60 \\
7\end{array}$ \\
\hline $\operatorname{ASA}(1: 2)$ & $13: 12$ & $12: 13$ & $14: 11$ & $\begin{array}{l}0.85 \\
2\end{array}$ \\
\hline $\begin{array}{l}\text { Duration of } \\
\text { pneumoperitoneum( } \\
\text { Min) }\end{array}$ & $\begin{array}{l}72 \pm \\
13.69\end{array}$ & $\begin{array}{l}71.18 \pm \\
11.16\end{array}$ & $\begin{array}{l}71.8 \pm \\
21.3\end{array}$ & $\begin{array}{l}0.99 \\
9\end{array}$ \\
\hline $\begin{array}{l}\text { Duration of surgery } \\
\text { (Min) }\end{array}$ & $\begin{array}{l}90 \pm \\
19\end{array}$ & $\begin{array}{l}86.60 \pm 13 \\
.5\end{array}$ & $\begin{array}{l}88 \pm 22 . \\
5\end{array}$ & $\begin{array}{l}0.81 \\
3\end{array}$ \\
\hline $\begin{array}{r}\text { Type of surgeries: } \\
\text { Upper abdominal } \\
\text { Lower abdominal }\end{array}$ & $\begin{array}{l}5 \\
20\end{array}$ & $\begin{array}{l}4 \\
21\end{array}$ & $\begin{array}{l}5 \\
20\end{array}$ & $\begin{array}{l}0.62 \\
3 \\
0.71 \\
8 \\
\end{array}$ \\
\hline
\end{tabular}

In all patients MAP was maintained within $20 \%$ of baseline with NTG infusion as necessary. Requirement of NTG was $16 \%$ patients in group C-IV, 0 patients in group C- IT and $36 \%$ of patients in group $\mathrm{N}$ (Figure 3). Among the 4 patients who required NTG in C-IV group, 2 patients underwent laparoscopic appendectomy, 1 patient diagnostic laparoscopy and 1 patient laparoscopic cholecystectomy. Among the 8 patients who required $\mathrm{NTG}$ in group $\mathrm{N}, 5$ patients underwent laparoscopic cholecystectomy, 1 patient diagnostic laparoscopy and 2 patients laparoscopic appendectomy.

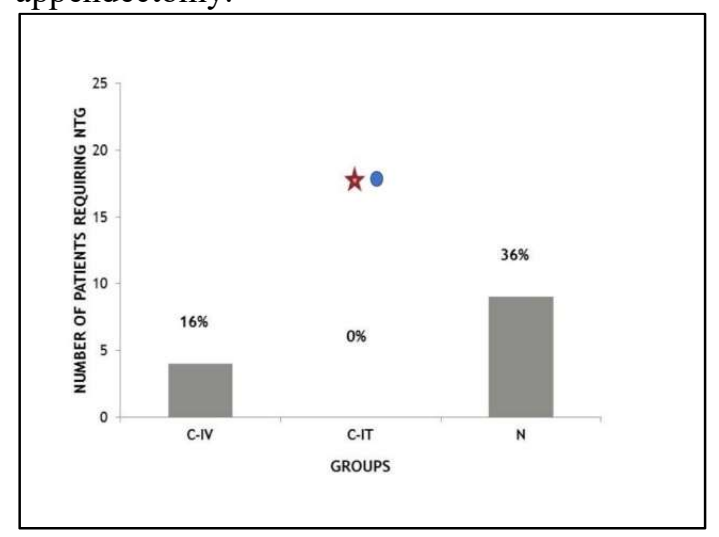

Figure 3: Percentage of patients requiring NTG in the different groups

스 Denotes significant difference 
between C-IT and C-IV ( $\mathrm{p}=0.04)$,

0 Denotes significant difference between C-IT and group $\mathrm{N}(\mathrm{p}=0.001)$.

There was a statistically significant difference in the number of patients who required NTG between group C- IT and group C- IV ( $\mathrm{p}=0.04)$ and between the group $\mathrm{C}$ - IT and group $\mathrm{N}$ $(p=0.001)$. The MAP was higher than baseline in group $\mathrm{N}$ compared to the other two groups. The MAP was consistently below the baseline (95 vs 90) throughout the period of observation in the IT group (Figure 4).

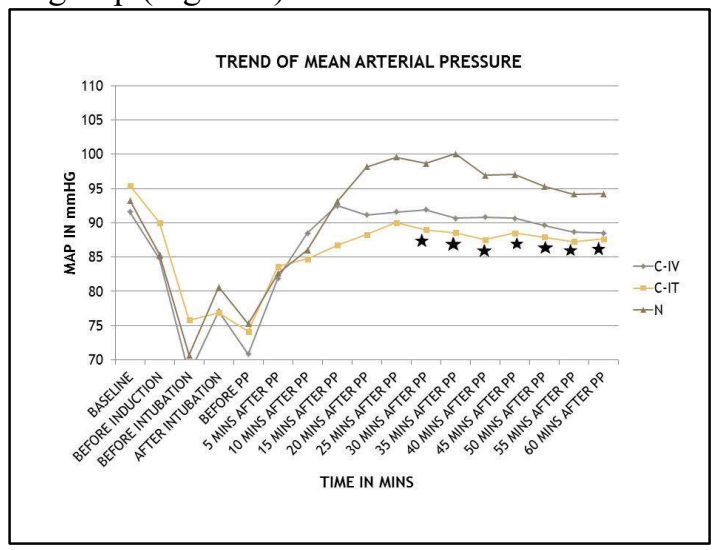

Figure 4: Trend of mean arterial pressure in the three groups. (Values are indicated as mean)

$\star \begin{aligned} & \text { Denotes the points where } \\ & \text { significant difference was noted }\end{aligned}$ between C-IT and group N.

The magnitude of maximum change in MAP is shown in Figure 5.

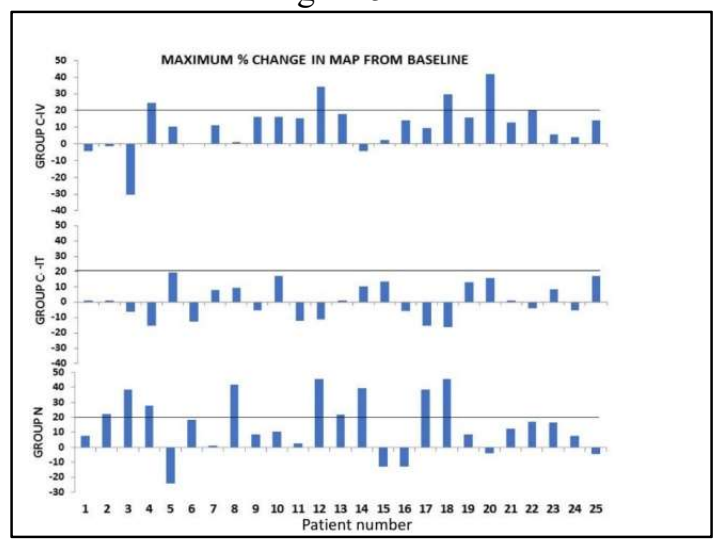

Figure 5: Magnitude of change in MAP following pneumoperitoneum as percentage change from baseline. Each bar represents an individual patient. Reference line indicates $20 \%$ change above baseline.

HR remained stable in all patients throughout the period of observation (Figure 6).

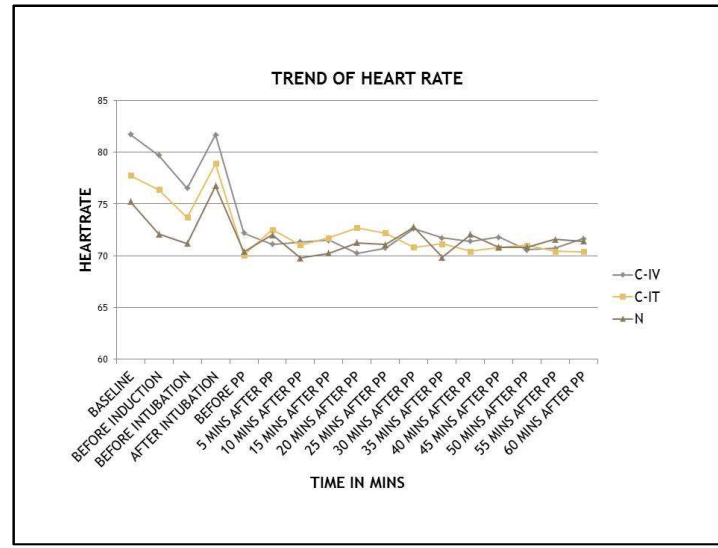

Figure 6: Trend of Heart rate in the three groups. (Values are indicated as mean).

The demand for rescue analgesia was $64 \%$ in group C-IV, $40 \%$ in group C-IT and $80 \%$ in group $\mathrm{N}$ in the first two hours. Significantly less number of patients in group C-IT required rescue analgesia than group $\mathrm{N}$.

None of the patients in any group were deeply sedated at extubation. Patients were either 'Awake and comfortable' or 'Asleep and arousable'. Relatively more patients (72\%) were awake in group $\mathrm{N}$ at extubation. All our patients were awake by $90 \mathrm{mins}$. There is no statistically significant difference in the sedation score between the groups.

Transient hypotension (systolic blood pressure $<$ $80 \mathrm{mmHg}$ ) was observed in 8 patients $(32 \%)$ in C-IV group at induction, which responded to $3 \mathrm{mg}$ bolus dose of mephenteramine. One patient in C-IV group developed intra-operative bradycardia that was treated with $0.3 \mathrm{mg}$ of atropine.

\section{Discussion}

The increase in MAP associated with pneumoperitoneum is the result of both increased IAP and hypercarbia. Abdominal muscle relaxation is an important confounding factor as inadequately relaxed muscles can cause an increase in IAP with consequent effects on haemodynamics. ${ }^{8}$ None of the studies so far have monitored the degree of neuro muscular paralysis. We used a TOF monitor as an objective method of maintaining neuro-muscular paralysis. In addition, MAC-age was monitored in all the patients and maintained constantly at 1.0 throughout the procedure and not altered based on haemodynamics. Most other studies 
previously done have increased the concentration of agents before starting on NTG. Standardizing the neuromuscular paralysis and the depth of anaesthesia has helped us to interpret the exact pharmacodynamic effects of the two different routes of clonidine.

The number of patients requiring NTG in study done by Tripathi et al was $46 \%$ in control group, $6 \%$ in the $1 \mu \mathrm{g} / \mathrm{kg}$ group and no patients in the $2 \mu \mathrm{g} / \mathrm{kg}$ group. ${ }^{10}$ Compared to our study less number of patients have required NTG in their study. This is probably because haemodynamics was managed initially by increasing the concentration of sevoflurane to $2 \%$ and only when the increase in MAP exceeded 20\% from the baseline despite $2 \%$ sevoflurane, it was treated with NTG. Omar et al studied the effects of $2 \mu \mathrm{g} / \mathrm{kg}$ IV clonidine in laparoscopic surgeries and observed that $6.566 \%$ patients required NTG. ${ }^{11}$

The central action of i.v. clonidine on the vasomotor center along with the sequential administration of other anesthetic drugs at induction (propofol, fentanyl) could have resulted in hypotension that was observed in 8 patients in C-IV group. Aho et al in his study described a significant decrease in MAP following induction after giving $4.5 \mu \mathrm{g} / \mathrm{kg}$ i.m. clonidine as premedication. ${ }^{15}$ In contrast to our observation, no hypotension was reported by Tripati et al on using $1 \mu \mathrm{g} / \mathrm{kg}$ i.v. clonidine. ${ }^{10}$ Filos et al compared 150, 300 and $450 \mu \mathrm{g}$ IT clonidine as a sole agent for post op analgesia following caesarean section and observed a decrease in MAP of more than 20\% from baseline with $150 \mu \mathrm{g}$ clonidine. ${ }^{20}$ We have not observed any hypotension in our study with $1 \mu \mathrm{g} / \mathrm{kg}$ IT clonidine. This can probably be due to our patients being subjected to a surgical stress and capnoperitoneum that countered the vasodilating properties of clonidine or due to the smaller dose of clonidine used.

Kumkum et al observed a significant decrease in HR from baseline in patients who were premedicated with $150 \mu \mathrm{g}$ of oral clonidine, but it was not severe enough to demand intervention. ${ }^{21}$ Filos et al observed that despite using $450 \mu \mathrm{g}$ of IT clonidine, none of the patients had bradycardia. ${ }^{20}$ Similar stability of HR was observed in our study too.

IT clonidine is commonly used as an adjuvant to spinal local anaesthetics to prolong the duration of analgesia. ${ }^{17,22}$ Only Filos et al have used IT clonidine as a sole analgesic for post op analgesia in caesarean section patients and they observed a dose dependent increase in duration of analgesia lasting for $402 \pm 75,570 \pm 76$ and $864 \pm 80 \mathrm{mins}$ when 150,300 and $450 \mu \mathrm{g}$ were used. $^{20}$ They have demonstrated that less clonidine is needed IT than systemically to produce strong analgesic effect lasting for longer duration. The effect of IT clonidine on postoperative analgesia could not be inferred from our study as the duration of analgesia was not assessed. However, we observed that IT clonidine provides good early post op analgesia as the number of patients who required rescue analgesia was less in this group compared to the other two groups. Although less number of patients in C-IT group required rescue analgesia, the difference was not statistically significant.

Tripathi et al have also observed that even with $2 \mu \mathrm{g} / \mathrm{kg}$ of i.v. clonidine, none of their patients were deeply sedated. ${ }^{10}$

The limitation of this study is that double blinding could not be done as the route of drug administration involved a technique, i.e. spinal in one group of patients. The other side effects of clonidine such as dry mouth, constipation and postural hypotension was also not followed up. Further, both upper abdominal and lower abdominal procedures were included in our study. So, we could not eliminate the influence of the two positions on haemodynamics. Direction for future research should be towards determining the risk vs benefit analysis of intrathecal vs intravenous clonidine.

\section{Conclusion}

In patients undergoing laparoscopy under $\mathrm{GA}, 1 \mu \mathrm{g} / \mathrm{kg}$ spinal clonidine produces better haemodynamics during insufflation and maintenance of capnoperitoneum than an equal dose of i.v. clonidine. Clonidine administration by both i.v. and i.t. route provides good early post op analgesia. At $1 \mu \mathrm{g} / \mathrm{kg}$ neither i.v. nor i.t. clonidine causes deep sedation delaying extubation or discharge from post-anaesthesia care unit.

\section{References}

1. O'Leary E, Hubbard K, Cunningham A. Laparoscopic cholecystectomy: Hemodynamic and neuroendocrine responses after pneumoperitoneum and changes in position. $\mathrm{Br} \mathrm{J}$ 
Anaethesia.1996;76:640-4.

https://doi.org/10.1093/bja/76.5.640

2. Wahba RW, Béique F, Kleiman SJ. Cardiopulmonary function and laparoscopic cholecystectomy. Can J Anaesth. 1995;42:5163.

https://doi.org/10.1007/BF03010572

PMid:7889585

3. Joris JL, Noirot DP, Legrand MJ, Jacquet NJ, Lamy ML. Hemodynamic changes during laparoscopic cholecystectomy. AnesthAnalg. 1993;76:1067-71.

https://doi.org/10.1213/00000539-199305000-

00027

PMid:8484509

4. Cunningham AJ. Anesthetic implications of laparoscopic surgery. Yale J Biol Med. 1998;71:551-78.

PMid:10604786 PMCid:PMC2578944

5. Koivusalo AM, Scheinin M, Tikkanen I, et al. Effects of esmolol on hemodynamic response to $\mathrm{CO} 2$ pneumoperitoneum for laparoscopic surgery. Acta Anaesthesiol Scand. 1998;42:5107.

https://doi.org/10.1111/j.1399-

6576.1998.tb05159.x

PMid:9605365

6. Damen SL, Nieuwenhuijs VB, Joosten W, Houweling PL, Clevers GJ. The effects of remifentanil and sufentanil on the quality of recovery after day care laparoscopic cholecystectomy: a randomized blinded trial. J Laparoendosc Adv Surg Tech A. 2004;14:87-92. https://doi.org/10.1089/109264204322973853 PMid:15107217

7. Neogi M, Basak S, Ghosh D, et al. A randomized double-blind placebo-controlled clinical study on the effects of gabapentin premedication on hemodynamic stability during laparoscopic cholecystectomy. J AnaesthesiolClinPharmacol. 2012;28:456-9. https://doi.org/10.4103/0970-9185.101903 PMid:23225923 PMCid:PMC3511940

8. Moon HS, Lee SK, Choi YS, In CB, Choi EJ. The effect of nitroglycerin on hemodynamic changes during laparoscopic low anterior resection. Korean J Anesthesiol. 2011;61:38893.

https://doi.org/10.4097/kjae.2011.61.5.388

PMid:22148087 PMCid:PMC3229017

9. Srivastava VK, Nagle V, Agrawal S, et al. Comparative evaluation of dexmedetomidine and esmolol on hemodynamic responses during laparoscopic cholecystectomy. J ClinDiagn Res 2015;9:UC01-05.

https://doi.org/10.7860/JCDR/2015/11607.5674

10. Tripathi DC, Shah KS, Dubey SR, Doshi SM, Raval PV. Hemodynamic stress response during laparoscopic cholecystectomy: Effect of two different doses of intravenous clonidine premedication. J AnaesthesiolClinPharmacol. 2011;27:475-80.

https://doi.org/10.4103/0970-9185.86586 PMid:22096279 PMCid:PMC3214551

11. Omar PK, Katiyar SK, Gupta V. Comparative study of intravenous nitroglycerine and clonidine on hemodynamic stability in laparoscopic cholecystectomy. J Evol Med Dent Sci. 2013;2:3239-48. https://doi.org/10.14260/jemds/690

12. Joris JL, Chiche J-D, Canivet J-LM, et al. Hemodynamic changes induced by laparoscopy and their endocrine correlates: effects of clonidine. J Am Coll Cardiol. 1998;32:1389-96. https://doi.org/10.1016/S0735-1097(98)00406-9

13. Eisanch JC, Tong C. Site of hemodynamic effects of intrathecal $\alpha 2$ - adrenergic agonists. Anesthesiology. 1991;74:766-71. https://doi.org/10.1097/00000542-199104000$\underline{00021}$

14. Sung CS, Lin SH, Chan KH, et al. Effect of oral clonidine premedication on perioperative hemodynamic response and postoperative analgesic requirement for patients undergoing laparoscopic cholycystectomy. Acta Anaesthesiol sin. 2000;38:23-9. PMid: 11000660

15. Aho M, Lehtinen A, Laatikinen T. Effects of intramuscular clonidine on hemodynamic and plama Beta Endorphin responses to Gynecologic Laparoscopy. Anaesthesiology. 1990;72:797802.

https://doi.org/10.1097/00000542-19900500000004

16. Kaur M, Liddle D, Verghese $M$, et al. The comparative evaluation of intravenous with intramuscular clonidine for suppression of hemodynamic changes in laparoscopic cholecystectomy. Saudi J Anaesth. 2013;7:1816.

https://doi.org/10.4103/1658-354X.114070 PMid:23956720 PMCid:PMC3737696

17. Kumar SK, Rao BK, Rao SS. A comparative study of intrathecal clonidine versus intravenous clonidine on duration of spinal bupivacaine. Int $\mathbf{J}$ Res Health Sci. 2014 Jul 31;2:920-5

18. Filos K, Goudas L, Patroni O, Polyzou V. Intrathecal clonidine as a sole analgesic for pain relief after cesarean section. Anaesthesiology. 1992;77:267-74.

https://doi.org/10.1097/00000542-19920800000008

19. Das S, Mitra K, Mandal M. Sample size calculation: Basic principles. Indian $\mathrm{J}$ Anaesth2016;60:652-6. https://doi.org/10.4103/0019-5049.190621 PMid:27729692 PMCid:PMC5037946

20. Filos K, Goudas L, Patroni O, Polyzou V. Hemodynamic and analgesic profile after intrathecal clonidine in Humans -A dose 
Rani et al. Sri Lankan Journal of Anaesthesiology: 26(2):111-117(2018)

response study. Anaesthesiology. 1994;81: 591601.

https://doi.org/10.1097/00000542-19940900000011

21. Gupta K, Sharma D, Gupta PK. Oral premedication with pregabalin or clonidine for hemodynamic stability during laryngoscopy and laparoscopic cholecystectomy: A comparative evaluation. Saudi J Anaesth. 2011;5:179-84. https://doi.org/10.4103/1658-354X.82791

PMid:21804800 PMCid:PMC3139312

22. Coombs DW, Saunders RL, Lachance D, et al. Intrathecal morphine tolerance: use of intrathecal clonidine, DADLE, and intraventricular morphine. Anesthesiology. 1985;62:358-63. https://doi.org/10.1097/00000542-19850300000028

PMid:3883851 